\title{
Impact of weight loss on oxidative stress and inflammatory cytokines in obese type 2 diabetic patients.
}

\author{
Shehab M. Abd El-Kader ${ }^{1}$, Mohammed H Saiem Al-Dahr ${ }^{2}$
}

1. Department of Physical Therapy, Faculty of Applied Medical Sciences, King Abdulaziz University.

2. Department of Medical Laboratory Technology, Faculty of Applied Medical Sciences, King Abdulaziz University.

\begin{abstract}
Background: Type 2 diabetes mellitus is associated with abnormal markers of inflammatory cytokines and oxidative stress markers. Although, these abnormalities could be modulated with weight reduction; there is limitation in clinical studies that have addressed the beneficial effects of weight reduction in modulating biomarkers of inflammatory cytokines and oxidative stress for obesity associated with type 2 diabetes mellitus.

Objective: This study was designed to detect the effects of weight loss on the inflammatory cytokines, oxidative stress markers in obese type 2 diabetic patients.

Material and Methods: Eighty obese patients with type 2 diabetes mellitus, their age ranged from 35-57 years and their body mass index ranged from $31-35 \mathrm{~kg} / \mathrm{m}^{2}$ were equally assigned into 2 groups: the weight reduction group received aerobic exercises, diet regimen, where as the control group received medical treatment only for 12 weeks.

Results: The mean values of body mass index (BMI), tumor necrosis factor-alpha (TNF- $\alpha$ ), interleukin-6 (IL-6), C-reactive protein (sCRP), conjugated dienes (CD) and malondialdehyde (MDA) were significantly decreased, while the mean values of glutathione peroxidase (GPx), superoxide dismutase (SOD) and glutathione (GSH) were significantly increased in patients of group (A), while changes were not significant in group (B). Also, there were significant differences between mean levels of the investigated parameters in group (A) and group (B) at the end of the study.

Conclusion: Weight loss ameliorates inflammatory cytokines and oxidative stress markers in obese type 2 diabetic patients.

Keywords: Type 2 diabetes, weight reduction, oxidative stress, cytokines, obesity.

DOI: http://dx.doi.org/10.4314/ahs.v16i3.12

Cite as: Abd El-Kader SM, Saiem Al-Dabr MH. Impact of weight loss on oxidative stress and inflammatory cytokines in obese type 2 diabetic patients. Afri Health Sci 2016;16(3): 725-733. DOI: bttp:/ / dx.doi.org/10.4314/abs.v16i3.12
\end{abstract}

\section{Introduction}

Type 2 diabetes mellitus (T2DM) is considered nowadays as a worldwide epidemic and it is responsible for approximately $90 \%$ of all cases of diabetes in the world, also it is one of the most important chronic disturbances because of the significant number of people with diabetes and its severe chronic complications, responsible for elevated indexes of morbidity and mortality ${ }^{1}$. According to World Health Organization (WHO), the global forward estimation is that in the year 2030, 366 million people will present the disease ${ }^{2}$. Patients with T2DM have a two-four

\section{Corresponding author:}

Shehab Mahmoud Abd El- Kader, Faculty of Applied Medical Sciences, Department of Physical Therapy,

King Abdulaziz University,

P.O. Box 80324, Jeddah, 21589,Saudi Arabia.

E-mail addresses: salmuzain@,kau.edu.sa times increased cardiovascular disease (CVD) risk compared to healthy controls ${ }^{3}$.

Adipose tissue represents an important source of cytokines, however excess body fat mass has been associated with increased levels of inflammatory cytokines such as TNF- $\alpha$ and IL- 6 4,5. Moreover, a decreased production of IL-10 by macrophages and lymphocytes has been associated with consequent increase of inflammatory responses in patients with Type 2 diabetes mellitus ${ }^{6}$. Low-grade systemic inflammation is characterized by a two to threefold increase in systemic plasma concentrations of cytokines such as tumor necrosis factor (TNF)- $\alpha$, interleukin (IL)6 and $\mathrm{C}$-reactive protein (CRP) ${ }^{7}$. However, diabetes impacts on the different steps in the pathogenesis of cardiovascular diseases $(\mathrm{CVD})^{8-10}$. T2DM is often associated with a "low-grade inflammatory status" accompanied by insulin resistance ${ }^{11}$. Obesity and IR in patients suffering from diabetes are associated with a chronic systemic inflammation, characterized by an increased expression of

African Health Sciences Vol 16 Issue 3, September 2016 
inflammatory markers. Multiple stimuli are among the most common causes of myocardial inflammation in cardiomyopathies in diabetic patients ${ }^{12-14}$. Systemic inflammatory markers are risk factors for the development of type 2 diabetes and its macro-vascular complications ${ }^{15}$. Oxidative stress plays a key role in the pathogenesis of micro- and macro-vascular diabetic complications. The increased oxidative stress in subjects with $\mathrm{T} 2 \mathrm{DM}$ is a consequence of several abnormalities, including hyperglycemia, IR, inflammation and dyslipidemia ${ }^{16}$. Oxidative stress causes insulin resistance, $\beta$-cell dysfunction and late diabetic complications ${ }^{17}$. It was demonstrated that markers of inflammation predict or/and are associated with T2DM and that inflammation is involved in the pathogenesis of atherosclerosis, a common feature of type 2 diabetes ${ }^{18}$. Free radicals are positively correlated with diabetic macro-vascular and micro-vascular complications ${ }^{19}$.

Obesity is associated with enhanced lipid peroxidation ${ }^{20}$. Oxidative stress is involved in pathological processes such as obesity, diabetes and cardiovascular diseases. Obese subjects have higher levels of oxidative stress biomarkers compared with control group ${ }^{21}$. Oxidative stress is known as the imbalance between oxidants and antioxidants in favor of the oxidants, potentially leading to cellular damage $^{22}$. Free radicals are reactive oxygen species (ROS) having an unpaired electron, which are generated under physiological conditions during aerobic metabolism. These free radicals have the potential to trigger chain reactions when they react with proteins, lipids and other biological molecules, which are fatal to the cell. Under normal conditions, the free radicals which are produced are scavenged by a repertoire of enzymatic antioxidants like SOD, catalase, glutathione peroxidase (GPx), etc. and also by non-enzymatic antioxidants like vitamin C, a-tocopherol, cerulo-plasmin, GSH etc., thus preventing the oxidative stress ${ }^{23,24}$.

Caloric restriction (CR), weight loss and exercise ameliorate the classic CVD risk factors hypertension and dyslipidemia among patients with $\mathrm{T}_{2} \mathrm{DM}^{25}$. In addition, weight loss and lifestyle interventions decrease plasma IL6 and $\mathrm{TNF} \alpha$ levels in obese non-diabetic subjects ${ }^{26}$. Therefore, the aim of this study was to assess the effects of weight loss on the inflammatory cytokines, oxidative stress markers in obese type 2 diabetic patients.

\section{Material and methods \\ Subjects}

The subjects were consecutively recruited among patients referred from the outpatient clinics of the Internal medicine department at King Abdul Aziz University Hospital and other Hospitals in Jeddah, Saudi Arabia. Inclusion criteria were age (42-55 years), body mass index (BMI) $30-35 \mathrm{~kg} / \mathrm{m}^{2}$ and type 2 diabetes mellitus. We excluded patients undergoing any kind of active treatment that affect the endothelial function, as well as pregnant women, those with chronic kidney or liver disease and those with congestive heart failure; uncontrollable cardiac arrhythmias, hypertension, musculoskeletal disorders. The subjects were allocated randomly into two study groups: either to the lifestyle intervention group (A) who received treadmill aerobic exercise training and diet regimen or to the control group (B) who received no exercise training and no diet regimen. The original sample consisted of 236 participants who underwent the eligibility assessment. In the enrollment phase, 104 of them were excluded as they didn't meet inclusion criteria and 32 refused to participate, then the randomization was done. This substudy thus included 109 subjects (59 patients in the intervention group and 50 patients in the control group). During the follow up, in the intervention group 6 patients discontinued intervention ( 3 patients disliked the diet regimen, 2 patients had work related schedule problems and 1 patient discontinued due to unknown reasons) and in the control group 3 patients discontinued intervention (2 patients had work related schedule problems and 1 patient discontinued due to unknown reason). In addition, 5 patients in the intervention group and 4 patients in the control group were excluded from the analysis due to insufficient blood sample. This study was approved by the Ethical Committee for Scientific Research, Faculty of Applied Medical Sciences, King Abdulaziz University. All participants provided written informed consent.

\section{Measurements}

In all subjects, clinical and anthropometric data was collected at the time of enrollment. Clinical evaluations and 
laboratory analysis were performed by independent assessors who were blinded to group assignment and not involved in the routine treatment of the patients. Body mass index (BMI) was calculated on the basis of weight (kilograms) and height (meters), and subjects were classified as normal weight (BMI 18.5-24.9 $\mathrm{kg} / \mathrm{m}^{2}$ ), overweight (BMI 25-29.9 kg/m²), and obese (BMI $\geq 30 \mathrm{~kg} /$ $\mathrm{m}^{2}$ ). In addition, between 07:30 and 09:00, after an overnight fast of $12 \mathrm{~h}$ fasting blood sample was drawn. The plasma lipid profile (total cholesterol, total triglycerides, high-density lipoprotein (HDL), and low-density lipoprotein (LDL), plasma glucose concentration and insulin were determined (Roche Diagnostics GmbH, Mannheim, Germany) using commercially available assay kits. Insulin resistance was assessed by homeostasis model assessment (HOMA-IR). HOMA-IR = fasting blood glucose $(\mathrm{mmol} / \mathrm{l})$ - fasting insulin $(\mathrm{mIU} / \mathrm{ml}) / 22.5^{27}$.

\section{A. Measurement of oxidative stress markers and an- ti-oxidant status:}

For all participants serum (from $10 \mathrm{ml}$ blood in plain vial) and plasma (from $5 \mathrm{ml}$ blood in EDTA vial) were separated from the sample within $30 \mathrm{~min}$ of collection and stored in pyrogen free polypropylene cryo-tubes at $\left(-80^{\circ} \mathrm{C}\right)$ until analysis. Assessment of lipid markers for peroxidation such as malondialdehyde (MDA) and conjugated dienes (CD) were determined according to Buege and Aust method. ${ }^{28}$. However, Anti-oxidant status, glutathione (GSH) was determined by the method of Beutler and colleagues ${ }^{29}$, on the other hand, glutathione peroxidase (GPx) and superoxide dismutase (SOD) were measured by the method of Nishikimi and colleagues ${ }^{30}$.

\section{B. Measurement of inflammatory cytokines:}

Venous blood samples after a 12-hours fasting were centrifuged at $4{ }^{\circ} \mathrm{C}(1000 \mathrm{X} \mathrm{g}$ for $10 \mathrm{~min})$. Interleukin-6 (IL6) levels were analyzed by "Immulite 2000 " immune-assay analyzer (Siemens Healthcare Diagnostics, Deerfield, USA). However, (TNF- $\alpha$ ), (sCRP) and interleukin-8 (IL8) levels were measured by ELISA kits (R\&D, USA) using ELISA technique (ELX 808; Bio-Tek Instruments, USA). All measurements of BMI, IL- 6 , TNF- $\alpha$, sCRP, MDA, $\mathrm{CD}, \mathrm{CPX}, \mathrm{GSH}$ and SOD were taken before the start of the study (pre-test) and after three months at the end of the study (post-test).

\section{Procedures}

We hypothesized that weight reducing program included treadmill aerobic exercise and diet regimen for 12 weeks would result in modulation in inflammatory cytokines and oxidative stress markers in obese patients with type 2 diabetes mellitus. As such, we randomized our subjects into either a training group(A) or a control group (B). As All patients were divided randomly into the following groups:

\section{The training group (Group A):}

Patients were submitted to the aerobic exercise training to complete a 12-week aerobic exercise-training program on a treadmill aerobic exercise (Enraf Nonium, Model display panel Standard, NR 1475.801, Holland). Each session of physical exercise was divided in: 5 min of warm up, with stretching exercises and circling of members and body; 30 min of aerobic exercise divided into row ergometer (15 min) and bicycle ergometer (15 min).; and 5 min of cold down at the end, with stretching, flexibility and relaxation exercises, consisting of five sessions per week. The training program was performed at $70 \%$ of the individual age-predicted HRmax according to Tanaka et al., ${ }^{31}$. In addition, a dietician performed an interview-based food survey for all participants of group (A) for detection of feeding habits, abnormal dietary behavior and to prescribe the balanced low calorie that provide 1200 Kilo calories/day for 12 weeks.

\section{The control group (Group B):}

Patients maintained their ordinary life style and received no exercise or diet regimen training.

\section{Statistical analysis}

All results are presented as means $\pm \mathrm{SD}$. The mean values of the investigated parameters obtained before and after the study. Independent " $t$ " test was used for the comparison between the two groups $(\mathrm{P}<0.05)$.

\section{Results}

The two groups considered homogeneous regarding the baseline clinical variables (Table 1). 
The mean values of body mass index (BMI), (TNF- $\alpha$ ), hyde (MDA) were significantly decreased, while the mean (IL-6), (sCRP), conjugated dienes (CD) and malondialde-

Table (1): Baseline clinical participants' characteristics in both groups

\begin{tabular}{|c|c|c|c|}
\hline & \multicolumn{2}{|c|}{ Mean \pm SD } & \multirow[b]{2}{*}{ Significance } \\
\hline & $\begin{array}{c}\text { Intervention group } \\
\text { (n:40) }\end{array}$ & $\begin{array}{c}\text { Control group } \\
(\mathbf{n}: 40)\end{array}$ & \\
\hline Age (year) & $48.36 \pm 5.12$ & $47.17 \pm 5.63$ & $\mathrm{P}>0.05$ \\
\hline Gender ( Male/Female) & $23 / 17$ & $21 / 19$ & $\mathrm{P}>0.05$ \\
\hline Weight $(\mathrm{kg})$ & $88.92 \pm 5.76$ & $90.11 \pm 6.24$ & $\mathrm{P}>0.05$ \\
\hline Height (cm) & $169.17 \pm 8.22$ & $171.37 \pm 7.81$ & $\mathrm{P}>0.05$ \\
\hline Waist-hip ratio & $0.86 \pm 0.05$ & $0.88 \pm 0.07$ & $\mathrm{P}>0.05$ \\
\hline BMI $\left(\mathrm{kg} / \mathrm{m}^{2}\right)$ & $31.85 \pm 3.46$ & $32.24 \pm 3.62$ & $\mathrm{P}>0.05$ \\
\hline SBP $(\mathrm{mm} \mathrm{Hg})$ & $123.41 \pm 7.23$ & $125.16 \pm 8.27$ & $\mathrm{P}>0.05$ \\
\hline DBP $(\mathrm{mm} \mathrm{Hg})$ & $82.65 \pm 6.81$ & $84.12 \pm 5.78$ & $\mathrm{P}>0.05$ \\
\hline TC (mg/dl) & $193.14 \pm 9.55$ & $195.26 \pm 10.17$ & $\mathrm{P}>0.05$ \\
\hline LDL-c (mg/dl) & $132.53 \pm 7.11$ & $135.16 \pm 8.26$ & $\mathrm{P}>0.05$ \\
\hline TG $(\mathrm{mg} / \mathrm{dl})$ & $154.05 \pm 9.25$ & $156.49 \pm 8.77$ & $\mathrm{P}>0.05$ \\
\hline HDL-c (mg/dl) & $35.21 \pm 2.15$ & $33.85 \pm 2.36$ & $\mathrm{P}>0.05$ \\
\hline HOMA-IR & $4.82 \pm 1.67$ & $4.96 \pm 1.44$ & $\mathrm{P}>0.05$ \\
\hline HbA1C (\%) & $7.66 \pm 1.58$ & $7.83 \pm 1.73$ & $\mathrm{P}>0.05$ \\
\hline Diabetes duration (year) & $11.16 \pm 2.11$ & $12.24 \pm 1.88$ & $\mathrm{P}>0.05$ \\
\hline
\end{tabular}

BMI: Body mass index; SBP: Systolic blood pressure; DBP: Diastolic blood pressure; TC: Total cholesterol; LDL-c: Low-density lipoprotein cholesterol; TG: Triglyceride; HDL-c: High-density lipoprotein cholesterol; HOMA-IR: Homeostasis Model Assessment-Insulin Resistance Index; HbA1C: Glycosylated hemoglobin; * Significant level $(\mathbf{p}<0.05)$.

values of glutathione peroxidase (GPx), superoxide dismutase (SOD) and glutathione (GSH) were significantly increased in patients of group (A) (Table 2), while chang- es were not significant in group (B) (Table 3).

Also, there were significant differences between mean levels of the investigated parameters in group (A) and group (B) at the end of the study (Table 4). 
Table (2): Mean value and significance of different variables such as (IL-6, TNF$\alpha$, SCRP, ICAM-1, VCAM-1and PAI-1: Ac) in-group (A) before and at the end of the study.

\begin{tabular}{|l|c|c|c|}
\hline \multirow{2}{*}{} & \multicolumn{2}{|c|}{ Mean \pm SD } & \multirow{2}{*}{ Significance } \\
\cline { 2 - 3 } & Before & After & \\
\hline BMI $\left(\mathrm{kg} / \mathrm{m}^{2}\right)$ & $31.85 \pm 3.46$ & $25.47 \pm 2.65^{*}$ & $\mathrm{P}<0.05$ \\
\hline TNF- $\boldsymbol{\alpha}(\mathrm{pg} / \mathrm{mL})$ & $11.94 \pm 2.63$ & $8.23 \pm 2.48^{*}$ & $\mathrm{P}<0.05$ \\
\hline IL-6 $(\mathrm{pg} / \mathrm{mL})$ & $5.87 \pm 1.34$ & $3.41 \pm 1.25^{*}$ & $\mathrm{P}<0.05$ \\
\hline sCRP $(\mathrm{mg} / \mathrm{L})$ & $4.26 \pm 1.22$ & $2.12 \pm 0.91^{*}$ & $\mathrm{P}<0.05$ \\
\hline CD $(\mathrm{mmol} / \mathrm{L})$ & $24.66 \pm 5.14$ & $18.72 \pm 4.15^{*}$ & $\mathrm{P}<0.05$ \\
\hline MDA $(\mathrm{mmol} / \mathrm{L})$ & $25.27 \pm 5.26$ & $19.13 \pm 4.32^{*}$ & $\mathrm{P}<0.05$ \\
\hline GPx $($ units/gHb) & $21.33 \pm 4.11$ & $26.22 \pm 3.73^{*}$ & $\mathrm{P}<0.05$ \\
\hline SOD $($ units/mL) & $43.51 \pm 5.57$ & $* 6.28 \pm 52.87$ & $\mathrm{P}<0.05$ \\
\hline GSH $(\mathrm{mmol} / \mathrm{gHb})$ & $2134.11 \pm 173.18$ & $2588.25 \pm 191.17^{*}$ & $\mathrm{P}<0.05$ \\
\hline
\end{tabular}

BMI: Body mass index; TNF- $\alpha$ : tumor necrosis factor - alpha; IL-6: Interleukin-6; sCRP: C- reactive protein; CD: conjugated dienes; MDA: Malondialdehyde; GPx: Glutathione peroxidase; SOD: Superoxide dismutase; GSH: Glutathione; * Significant level $(\mathrm{p}<0.05)$.

Table (3): Mean value and significance of different variables such as (IL-6, TNF$\alpha$, sCRP, ICAM-1, VCAM-1and PAI-1: Ac) in-group (B) before and at the end of the study.

\begin{tabular}{|l|c|c|c|}
\hline \multirow{2}{*}{} & \multicolumn{2}{|c|}{ Mean +SD } & \multirow{2}{*}{ Significance } \\
\cline { 2 - 3 } & Before & After & \\
\hline BMI $\left(\mathrm{kg} / \mathrm{m}^{2}\right)$ & $32.24 \pm 3.62$ & $32.41 \pm 3.68$ & $\mathrm{P}>0.05$ \\
\hline TNF- $\boldsymbol{\alpha}(\mathrm{pg} / \mathrm{mL})$ & $12.13 \pm 2.54$ & $12.26 \pm 2.56$ & $\mathrm{P}>0.05$ \\
\hline IL-6 $(\mathrm{pg} / \mathrm{mL})$ & $5.91 \pm 1.43$ & $5.95 \pm 1.61$ & $\mathrm{P}>0.05$ \\
\hline sCRP $(\mathrm{mg} / \mathrm{L})$ & $4.43 \pm 1.29$ & $4.51 \pm 1.32$ & $\mathrm{P}>0.05$ \\
\hline CD $(\mathrm{mmol} / \mathrm{L})$ & $25.17 \pm 4.76$ & $25.68 \pm 4.79$ & $\mathrm{P}>0.05$ \\
\hline MDA $(\mathrm{mmol} / \mathrm{L})$ & $25.36 \pm 5.12$ & $25.72 \pm 5.26$ & $\mathrm{P}>0.05$ \\
\hline GPx $($ units/gHb) & $20.98 \pm 3.75$ & $20.63 \pm 3.41$ & $\mathrm{P}>0.05$ \\
\hline SOD $($ units/mL) & $43.16 \pm 5.14$ & $42.77 \pm 4.96$ & $\mathrm{P}>0.05$ \\
\hline GSH $(\mathrm{mmol} / \mathrm{gHb})$ & $2091.30 \pm 162.72$ & $2064.83 \pm 151.41$ & $\mathrm{P}>0.05$ \\
\hline
\end{tabular}

BMI: Body mass index; TNF- $\alpha$ : tumor necrosis factor - alpha; IL-6: Interleukin-6; sCRP: Creactive protein; CD: conjugated dienes; MDA: Malondialdehyde; GPx: Glutathione peroxidase; SOD: Superoxide dismutase; GSH: Glutathione.

Discussion
Type 2 diabetes mellitus is the most prevalent metabolic disease in the world ${ }^{32}$, which is related to vascular prob-

African Health Sciences Vol 16 Issue 3, September 2016 


\section{Table (4): Mean value and significance of (IL-6, TNF- $\alpha$, sCRP, ICAM-1, VCAM-1 and PAI-1: Ac) in group (A) and group (B) at the end of the study.}

\begin{tabular}{|l|c|c|c|}
\hline & \multicolumn{2}{|c|}{ Mean +SD } & \multirow{2}{*}{ Significance } \\
\cline { 2 - 3 } & Group (A) & Group (B) & \\
\hline BMI $\left(\mathrm{kg} / \mathrm{m}^{2}\right)$ & $25.47 \pm 2.65^{*}$ & $32.41 \pm 3.68$ & $\mathrm{P}<0.05$ \\
\hline TNF- $\boldsymbol{\alpha}(\mathrm{pg} / \mathrm{mL})$ & $* 8.23 \pm 2.48$ & $12.26 \pm 2.56$ & $\mathrm{P}<0.05$ \\
\hline IL-6 $(\mathrm{pg} / \mathrm{mL})$ & $3.41 \pm 1.25^{*}$ & $5.95 \pm 1.61$ & $\mathrm{P}<0.05$ \\
\hline sCRP $(\mathrm{mg} / \mathrm{L})$ & $2.12 \pm 0.91^{*}$ & $4.51 \pm 1.32$ & $\mathrm{P}<0.05$ \\
\hline CD $(\mathrm{mmol} / \mathrm{L})$ & $18.72 \pm 4.15^{*}$ & $25.68 \pm 4.79$ & $\mathrm{P}<0.05$ \\
\hline MDA $(\mathrm{mmol} / \mathrm{L})$ & $* 19.13 \pm 4.32^{*}$ & $25.72 \pm 5.26$ & $\mathrm{P}<0.05$ \\
\hline GPx $($ units/gHb) & $26.22 \pm 3.93^{*}$ & $20.63 \pm 3.41$ & $\mathrm{P}<0.05$ \\
\hline SOD $($ units/mL) & $52.87 \pm 6.28^{*}$ & $42.77 \pm 4.96$ & $\mathrm{P}<0.05$ \\
\hline GSH $(\mathrm{mmol} / \mathrm{gHb})$ & $2588.25 \pm 191.17^{*}$ & $2064.83 \pm 151.41$ & $\mathrm{P}<0.05$ \\
\hline
\end{tabular}

BMI: Body mass index; TNF- $\alpha$ : tumor necrosis factor - alpha; IL-6: Interleukin-6; sCRP: C- reactive protein; CD: conjugated dienes; MDA: Malondialdehyde; GPx: Glutathione peroxidase; SOD: Superoxide dismutase; GSH: Glutathione; * Significant level $(p<0.05)$.

lems ${ }^{33,34}$. The American Heart Association recommended weight loss to reduce the severity of cardiovascular risk factors in overweight and obese patients ${ }^{35}$. The main finding of the present study was that weight reducing program ameliorated inflammatory cytokines (TNF- $\alpha$, IL-6, sCRP) and markers of oxidative and anti-oxidative stress (MDA, CD, CPX, GSH and SOD) in obese patients with type 2 diabetes mellitus as a result of weight loss, these results are in line with many previous studies.

The effect of dietary interventions on sCRP levels has been studied in obese non-diabetic subjects. Weight loss was clearly associated with a decrease in sCRP in these subjects and related to the amount of weight $\operatorname{loss}^{36}$. In obese non-diabetic patients, diet, exercise or combined interventions have controversial effects on plasma IL-6 and $\mathrm{TNF}-\alpha$ level ${ }^{37-43}$. Sheu and colleagues reported that $5 \%$ of body weight loss obtained after 12 weeks of caloric restriction and exercises resulted in significant reduction in TNF- $\alpha$ and IL- 6 of obese women ${ }^{44}$. Lang and colleagues established that a weight-reducing program had anti-atherogenic and inflammatory effects in their study on three obese men and eleven obese women for eight weeks ${ }^{45}$. Choo and colleagues proved that weightreducing program in the form of diet regimen for three months followed by diet regimen added to exercise intervention for nine months had a remarkable reduction in the risk of cardio-metabolic and subclinical atherosclerosis ${ }^{46}$. Madsen and colleagues stated that inflammatory markers were reduced significantly if body weight was reduced by $10 \%$ in obese subjects ${ }^{47}$. Esposito e al. suggested that weight-reducing program for 2 years significantly reduced C-reactive protein ${ }^{48}$. In addition, Nicklas and colleagues stated that 12 months life style modification program significantly reduced $\mathrm{TNF}-\alpha$ level in obese individuals ${ }^{49}$. Reductions in pro-inflammatory cytokines concentrations after weight loss is explained by reduction in fat mass $^{50}$.

Concerning the markers of oxidative and anti-oxidative stress, the observation in this study indicated a significant reduction in MDA \& $\mathrm{CD}$ and increased in CPX, GSH and SOD as a result of weight loss at the end of the study. Nevertheless, the current data is in line with one previous study by Roberts et al. Proved that after three weeks of combination between diet and exercise there was a significant reduction in BMI, lipid profile, fasting blood sugar, sCRP and insulin homeostasis which ameliorates oxidative stress, inflammation and monocytesendothelial interaction among diabetic patients ${ }^{51}$. 
The possible mechanism for modulation of the oxidative stress markers induced by weight reduction could be due to reverse the mechanism by which obesity produces oxidative stress. The first of these is the mitochondrial and peroxisomal oxidation of fatty acids, which can produce ROS in oxidation reactions, while another mechanism is over-consumption of oxygen, which generates free radicals in the mitochondrial respiratory chain that is found coupled with oxidative phosphorylation in mitochondria. Lipid-rich diets are also capable of generating ROS because they can alter oxygen metabolism ${ }^{52}$. So that upon reduction of adipose tissue, the activity of antioxidant enzymes such as SOD, catalase (CAT), and GPx, was found to be significantly increased.

\section{Conclusion}

Weight loss ameliorates inflammatory cytokines and oxidative stress markers in obese type 2 diabetic patients.

\section{Acknowledgment}

This project was funded by the Deanship of Scientific Research (DSR), King Abdulaziz University, Jeddah, under grant no. (142/4/D1436). The authors, therefore, acknowledge with thanks DSR technical and financial support.

\section{References}

1. Cruz NG, Sousa LP, Sousa MO, Pietrani NT, Fernandes AP, Gomes KB. The linkage between inflammation and Type 2 diabetes mellitus. Diabetes Res Clin Pract 2013; 99 (2):85-92.

2. Li R, Lu W, Jiang QW, Li YY, Zhao GM, Shi L, et al. Increasing prevalence of Type 2 diabetes in Chinese adults in Shanghai. Diabetes Care 2012;35(5):1028-30. PubMed 3. Stamler J, Vaccaro O, Neaton JD, Wentworth D. Diabetes, other risk factors, and 12-yr cardiovascular mortality for men screened in the Multiple Risk Factor Intervention Trial. Diabetes Care 1993; 16: 434 - 444. PubMed

4. Carvalho MHC, Colac o AL, Fortes ZB. Citocinas Disfunc $_{s} \mathrm{a}^{\circ}$ Endotelial e Resiste^ncia a`Insulina. Arq Bras Endocrinol Metab 2006:50(2):304-12.

5. DandonaP, Aljada A, Bandyopadhyay A. Inflammation: the link between insulin resistance, obesity and diabetes. Trends Immunol 2004; 25(1):4-7. PubMed

6. Exel EV, Gussekloo J, Craen AJM, Frolich M, Wiel AB, Westendorp RGJ. Low production capacity of interleu- kin-10 associates with the metabolic syndrome and Type 2 diabetes. Diabetes 2002;51:1088-92. PubMed

7. Petersen AM, Pedersen BK. The anti-inflammatory effect of exercise. J Applied Physiol 2005;98:1154-62. PubMed

8. Dobrin JS, Lebeche D. Diabetic cardiomyopathy: signaling defects and therapeutic approaches. Expert Rev Cardiovasc Ther 2010;8: 373-391.

9. Opie LH, Yellon DM, Gersh BJ. Controversies in the cardiovascular management of type 2 diabetes. Heart 2011;97: 6-14. PubMed

10. Singh S, Dhingra S, Ramdath DD, Vasdev S, Gill V, Singal PK. Risk factors preceding type 2 diabetes and cardiomyopathy. J Cardiovasc Transl Res 2010; 3: 580-596.

11. Vaarala O, Yki-Jarvinen H. Diabetes: should we treat infection or inflammation to prevent T2DM? Nature Reviews. Endocrinology 2012; 8: 323-325. PubMed

12. Herder C, Karakas M, Koenig W. Biomarkers for the prediction of type 2 diabetes and cardiovascular disease. Clin Pharmacol Ther 2011; 90: 52- 66. PubMed

13. Marchant DJ, Boyd JH, Lin DC, Granville DJ, Garmaroudi FS, McManus BM. Inflammation in myocardial diseases. Circ Res 2012; 110: 126-144. PubMed

14. Taube A, Schlich R, Sell H, Eckardt K, Eckel J . Inflammation and metabolic dysfunction: links to cardiovascular diseases. Am J Physiol Heart Circ Physiol 2012; 302: H2148-H2165.

15. Esser N, Legrand-Poels S, Piette J, Scheen AJ, Paquot N. Inflammation as a link between obesity, metabolic syndrome and type 2 diabetes. Diabetes Res Clin Pract 2014; 105(2):141-50.

16. Paoletti R, Bolego C, Poli A, Cignarella A. Metabolic syndrome, inflammation and atherosclerosis. Vasc Health Risk Manag 2006; 2:145-152.

17. Evans JL, Goldfine ID, Maddux BA, Grodsky GM. Are oxidative stress activated signaling pathways mediators of insulin resistance and beta-cell dysfunction?. Diabetes 2003; 52: 1-8.

18. Pickup JC. Inflammation and activated innate immunity in the pathogenesis of type 2 diabetes, Diabetes Care 2004; 27: 813-823. PubMed

19. Chaudhuri A, Umpierrez GE. Oxidative stress and inflammation in hyperglycemic crises and resolution with insulin: implications for the acute and chronic complications of hyperglycemia. Journal of Diabetes and its Complications 2012;26: 257-258. 
20. Murdolo G, Piroddi M, Luchetti F, Tortoioli C, Canonico $\mathrm{B}$, Zerbinati $\mathrm{C}$, et al. Oxidative stress and lipid peroxidation by-products at the crossroad between adipose organ dysregulation and obesity-linked insulin resistance. Biochimie 2012;95(3):585-94. PubMed

21. Keaney Jr, Larson MG, Vasan RS, Wilson PW, Lipinska I, Corey D, et al. Obesity and systemic oxidative stress: clinical correlates of oxidative stress in the Framingham study. Arterioscler Thromb Vasc Biol 2003; 23:434-9.

22. Iuliano L. Pathways of cholesterol oxidation via nonenzymatic mechanisms. Chem Phys Lipids 2011; 164:45768. PubMed

23. Mataix J, Quiles JL, Heurtas JR, Battino M, Manas M. Tissue specific interactions of exercise, dietary fatty acids, and vitamin $\mathrm{E}$ in lipid peroxidation. Free Radic Biol Med 1998; 24:511-21. PubMed

24. Saad EA. Curative and protective effects of L-arginine on carbon tetrachloride- induced hepatotoxicity in mice. Biochem Biophys Res Commun 2012; 423: 147-51.

25. Roberts CK, Barnard RJ. Effects of exercise and diet on chronic disease. J Appl Physiol 2005; 98: 3-30. PubMed 26. Herder C, Peltonen M, Koenig W, Sutfels K, Lindstrom J, Martin S, Ilanne-Parikka P, Eriksson JG, Aunola S, Keinanen-Kiukaanniemi S, Valle TT, Uusitupa M, Kolb $\mathrm{H}$, Tuomilehto J. Anti-inflammatory effect of lifestyle changes in the Finnish Diabetes Prevention Study. Diabetologia 2009; 52: 433-442.

27. Matthews DR, Hosker JP, Rudenski AS, Naylor BA, Treacher DF, Turner RC. Homeostasis model assessment: insulin resistance and beta cell function from plasma FBS and insulin concentrations in man. Diabetologia 1985; 28:412-9. PubMed

28. Buege JA, Aust SD. Microsomal lipid peroxidation. Methods Enzymol 1978; 52:302-310. PubMed

29. Beutler E, Duron O, Kelly BM. Improved method for the determination of blood glutathione. J Lab Clin Med 1963;61:882-888. PubMed

30. Nishikimi M, Appaji Rao N, Yagi K. The occurrence of superoxide anion in the reaction of reduced phenazine methosulfate and molecular oxygen. Biochem Biophys Res Commun 1972; 46:849-854.

31. Tanaka H, Monahan K, Seals D. Age-predicted maximal heart rate revisited. J Am Coll Cardiol 2001; 37: 153156. PubMed

32. Donath MY, Shoelson SE. Type 2 diabetes as an inflammatory disease. Nat Rev Immunol 2011; 11:98-107. PubMed

African Health Sciences Vol 16 Issue 3, September 2016
33. Avogaro A, Albiero M, Menegazzo L, de Kreutzenberg S, Fadini GP. Endothelial dysfunction in diabetes: the role of reparatory mechanisms. Diabetes Care 2011; 34 (Suppl 2): S285-290.

34. Ding H, Triggle CR . Endothelial dysfunction in diabetes: multiple targets for treatment. Pflugers Arch 2010; 459: 977-994.

35. Klein S, Burke LE, Bray GA. Clinical implications of obesity with specific focus on cardiovascular disease: a statement for professionals from the American Heart Association Council on Nutrition, Physical Activity, and Metabolism: Endorsed by the American College of Cardiology Foundation. Circulation 2004;110:2952-2967 .

36. Selvin E, Paynter NP, Erlinger TP. The effect of weight loss on C-reactive protein: a systematic review. Arch Intern Med 2007; 167: 31-39. PubMed

37. Herder C, Peltonen M, Koenig W, Sutfels K, Lindstrom J, Martin S, Ilanne- Parikka P, Eriksson JG, Aunola S, Keinanen-Kiukaanniemi S, Valle TT, Uusitupa M, Kolb $\mathrm{H}$, Tuomilehto J. Anti-inflammatory effect of lifestyle changes in the Finnish Diabetes Prevention Study. Diabetologia 2009;52: 433-442. PubMed

38. You T, Berman DM, Ryan AS, Nicklas BJ. Effects of hypocaloric diet and exercise training on inflammation and adipocyte lipolysis in obese postmenopausal women. J Clin Endocrinol Metab 2004; 89: 1739-1746.

39. Ziccardi P, Nappo F, Giugliano G, Esposito K, Marfella R, Cioffi M, D’Andrea F, Molinari AM, Giugliano D. Reduction of inflammatory cytokine concentrations and improvement of endothelial functions in obese women after weight loss over one year. Circulation 2002; 105: 804-809. PubMed

40. Wegge J, Roberts CK, Ngo TH, Barnard RJ. Effect of diet and exercise intervention on inflammatory and adhesion molecules in postmenopausal women on hormone replacement therapy and at risk for coronary artery disease. Metabolism 2004; 53: 377-381. PubMed

41. Bruun JM, Helge JW, Richelsen B, Stallknecht B.. Diet and exercise reduce low-grade inflammation and macrophage infiltration in adipose tissue but not in skeletal muscle in severely obese subjects. Am J Physiol Endocrinol Metab 2006; 290:E961-E967.

42. Christiansen T, Paulsen SK, Bruun JM, Pedersen $\mathrm{SB}$, Richelsen B. Exercise training versus diet-induced weight-loss on metabolic risk factors and inflammatory markers in obese subjects: a 12-week randomized intervention study. Am J Physiol Endocrinol Metab 2010; 298: E824-E831. 
43. Klimcakova E, Polak J, Moro C, Hejnova J, Majercik M, Viguerie N, Berlan M, Langin D, Stich V. Dynamic strength training improves insulin sensitivity without altering plasma levels and gene expression of Adipokines in subcutaneous adipose tissue in obese men. J. Clin. Endocrinol. Metab 2006; 91: 5107- 5112. PubMed

44. Sheu WH, Chang TM, Lee WJ, Ou HC, Wu CM, Tseng LN, Lang HF, Wu CS, Wan CJ, Lee IT. Effect of weight loss on pro-inflammatory state of mononuclear cells in obese women. Obesity (Silver Spring) 2008,16(5):1033-8. PubMed

45. Lang HF, Chou CY, Sheu WH, Lin JY. Weight loss increased serum adiponectin but decreased lipid levels in obese subjects whose body mass index was lower than 30 $\mathrm{kg} / \mathrm{m}^{2}$. Nutr Res 2011; 31(5):378-86. PubMed

46. Choo J, Lee J, Cho JH, Burke LE, Sekikawa A, Jae SY. Effects of weight management by exercise modes on markers of subclinical atherosclerosis and cardiometabolic profile among women with abdominal obesity: a randomized controlled trial. BMC Cardiovasc Disord 2014; 10: $14: 82$.

47. Madsen EL, Rissanen A, Bruun JM. Weight loss larger than $10 \%$ is needed for general improvement of levels of circulating adiponectin and markers of inflammation in obese subjects: a 3-year weight loss study. Eur J Endocrinol 2008;158(2):179-187. PubMed

48. Ryan AS, Nicklas BJ, Berman DM, Elahi D. Adiponectin levels do not change with moderate dietary induced weight loss and exercise in obese postmenopausal women. Int J Obes Relat Metab Disord 2003; 27:1066-71. 49. Nicklas BJ, You T, Pahor M. Behavioral treatments for chronic systemic inflammation: effects of dietary weight loss and exercise training. CMAJ 2005; 172:1199-209.

50. Marfella R, Esposito K, Siniscalchi M. Effect of weight loss on cardiac synchronization and proinflammatory cytokines in premenopausal obese women. Diabetes Care 2004; 27,47-52. PubMed

51. Roberts CK, Won D, Pruthi S, Lin SS, Barnard RJ. Effect of a diet and exercise intervention on oxidative stress, inflammation and monocyte adhesion in diabetic men. Diabetes Res Clin Pract 2006;73(3):249-59.

52. Ferna'ndez-Sa'nchez A, Madrigal-Santilla'n E, Bautista M, Esquivel-Soto J, Mor- ales-Gonza' lez A, Esquivel-Chirino $\mathrm{C}$, et al. Inflammation, oxidative stress, and 544 obesity. Int J Mol Sci 2011; 12(5),:3117-32. PubMed 